\title{
Checking the health of school entrants
}

\author{
K Whitmore, M C O Bax
}

For almost 70 years until 1974 children were legally obliged to be examined by a doctor at school. Among the reasons for this were 'the early detection of unsuspected defects' and 'checking incipient maladies at their outset'. ${ }^{1} \mathrm{At}$ one time statutory regulations required routine periodic medical inspections at three specified ages between entering and leaving school, but from 1959 local education authorities were allowed to introduce more selective arrangements. These became the vogue in the 1960s for children during their middle school years but only one education authority opted for selective rather than routine medical examinations of children on entry to school. Until five years ago $90 \%$ of district health authorities still favoured routine examinations at this stage (C R Haines, personal communication). Furthermore, as a result of the greatly improved physical health of schoolchildren and the relative increase in developmental and behavioural disorders, school doctors have been paying more attention at these entrant examinations to the children's cognitive and social development; such developmental assessment has long been an important feature in the programme of health care for preschool children.

There is now mounting evidence, both factual and hearsay, for either the adoption of selective medical examinations of school entrants or even the elimination of examination by a doctor and reliance on a routine health check by school nurses. For instance, O'Callaghan and Colver in arguing for selective medical examinations maintain that at the age of 5 , new important treatable abnormal physical conditions that can only be detected by a doctor are too rare to justify a doctor seeing all school entrants. ${ }^{2}$ They also maintain that the more common disorders of learning and behaviour are too difficult for a doctor to assess at their examinations, and that such assessments are anyway unnecessary as the disorders invariably come to light in the course of time in school, and their assessment is strictly the responsibility of educational psychologists.

The British Paediatric Association (BPA) also considers routine entrant medical examination unnecessary if an effective preschool service has been established and medical information is efficiently transmitted between preschool and school health services ${ }^{3}$ The BPA did not suggest that this is generally the case at present but even before their advice had been given a number of health authorities had abandoned these examinations. This step had been precipi- tated by a serious shortage of funds but rationalised by popular misconceptions about screening and the role of the doctor in promoting health. Their argument goes something like this: the doctor's examination is no more than a screening procedure; screening is a paramedical function best carried out by nurses because a school nursing service is probably more cost effective than the employment of doctors to carry out regular school medicals; this saves the authority money but it also leaves the doctors more time for more important aspects of educational medicine, which suits them because they see the work in terms of diagnosis and treatment of disease. $^{2-7}$

This argument is specious - and not only because it results in a reduction rather than a redeployment of medical time; in this and in other ways it can only lead to a further deterioration in the quality of care from a service already severely compromised as we shall hope to show in answering the following three questions:

(1) How effective might nurses be in identifying problems?

(2) Does it matter if neurodevelopmental problems are missed?

(3) How much money might be saved by nurse only health check of entrants?

(1) How effective might nurses be in identifying problems?

It is not of course true that a doctor's examination of all school entrants is no more than a screening procedure, as generally understood and meeting agreed criteria. ${ }^{89}$ It is a clinical procedure requiring a considered judgment (assessment) of each child's state of health, and therefore better referred to as a health check. ${ }^{10}$ Checking entrants' health is not the sole prerogative of doctors but when carried out by nurses it still does not become just a population screening however often this is incorrectly said to be so. Both doctors and nurses may occasionally use genuine screening techniques in checking health.

Nevertheless, absence of disease remains one characteristic of health and so the early identification of unsuspected or incipient disorder (developmental and behavioural no less than physical and sensory) has to be one objective of a health check. If it is to be left entirely to the nurses we have to be sure that they can identify any disorder (that is, recognise or suspect its 
presence) as certainly as doctors. One previous American study in particular showed how mass screening (so called) by health aides identified a greater number of problems than did physical examinations (by trained school nurse practitioners), ${ }^{11}$ but the examinations identified more problems per 100 contacts and $85 \%$ of those problems were of a kind for which screening was inappropriate. These findings were from a study of schoolchildren of all ages, not solely entrants, and did not include neurodevelopmental testing.

In the absence of data from other prospective studies we have looked back at our own data from a study of health service needs in 12 primary schools in Paddington, an inner city district of London, in which 351 school entrants were examined by doctor and nurse. ${ }^{12}$ In retrospect we wanted to compare the actual results from these joint examinations with those that theoretically we might have expected had the nurses been responsible on their own for checking health and development. The answer would depend on how much of the examination they could have done alone. We have already described our joint examination in detail, ${ }^{13}$ and obviously they could do all they did then. They perused all available preschool health records; they weighed and measured each child, recording the readings on Tanner-Whitehouse age percentile charts; they tested and recorded near, distant, and colour vision; and they gave each child a pure tone audiometric sweep test (the only true screening technique they employed). They also completed a parent interview schedule (PIS). In retrospect they could certainly have checked each child's weight on Chinn-Morris height percentile charts, ${ }^{14}$ and measured head circumference, both of which the doctors did in the study. We could assume also (couldn't we?) that with the child stripped for weighing they could have inspected exposed parts for skin disease and for state of trunk and limbs. We see no reason why they should not have used an auriscope to look for wax or other obstruction in the external auditory meatus; school nurses already do in some districts. Absence of, or uncertainty on perusal of preschool records would have meant automatic referral of the child to the doctor who would have then routinely carried out a comprehensive examination; so would a history of not speaking clearly in sentences by the age of 3 and parental worry about the child's behaviour at home or bedwetting, when the doctor would routinely have done a neurodevelopmental examination. We do not think the school nurse could do such an examination in full, at least not without a lot more training, and it is undesirable that it be carried out piecemeal. For instance, while she could be trained to test speech discrimination it is preferable not to separate this from tests of speech, language, and other aspects of mental development.

The results of nurses' health checks of entrants that might have been expected under the above circumstances are shown in table 1 , where they are compared with the actual results from the joint examinations. The latter brought to light 462 problems (suspected disorders) for
Table 1 Nature and number of problems actually identified by joint examinations and theoretically identifiable by nurses' health checks ( 351 school entrants)

\begin{tabular}{|c|c|c|}
\hline Nature of problem & $\begin{array}{l}\text { Identified } \\
\text { by joint } \\
\text { examination }\end{array}$ & $\begin{array}{l}\text { Identifiable } \\
\text { by nurse } \\
\text { only health } \\
\text { check }\end{array}$ \\
\hline $\begin{array}{l}\text { Physical conditions } \\
\text { Failed vision test } \\
\text { Failed hearing test } \\
\text { Parent worried about behaviour } \\
\text { Parent worried about bedwetting }\end{array}$ & $\begin{array}{l}57 \\
37 \\
58 \\
39 \\
14\end{array}$ & $\begin{array}{l}45 \\
37 \\
58 \\
39 \\
14\end{array}$ \\
\hline Total & 205 & 193 \\
\hline $\begin{array}{l}\text { Failed speech test } \\
\text { Failed speech and language tests } \\
\text { Failed language test only } \\
\text { Delay in cognitive development }\end{array}$ & $\begin{array}{l}11 \\
34(\times 2) \\
87 \\
91\end{array}$ & $\begin{array}{l}9 \\
20(\times 2) \\
36 \\
52\end{array}$ \\
\hline $\begin{array}{l}\text { Total No of problems } \\
\text { No of children with problems }\end{array}$ & $\begin{array}{l}462 \\
232\end{array}$ & $\begin{array}{l}330 \\
182\end{array}$ \\
\hline
\end{tabular}

which 232 children (66\% of all the entrants) were given appointments for a review within three months or so. On their own the nurses might have been able to identify $72 \%$ of the problems, or more importantly bring before the doctor $78 \%$ of the children with suspected disorders.

They could have identified four out of five of the physical conditions, all the sensory, behavioural (including bedwetting) problems and approximately half those relating to delay in speech, language, or cognitive development in so far as these would have been detected if the doctor carried out a neurodevelopmental examination on children referred for the four reasons stated above. Twelve of the physical problems listed separately in table 2 (all but two of which had not been 'suspected' by the parents), would have been missed: five undescended testes, three congenital heart defects, and four ear, nose, and throat conditions. From the PIS and their own observations the nurses might have picked up some of the ear, nose, and throat disorders but not the others; however, at the most this would have increased the proportion of problems identified by only $1 \%$ as the great majority of the problems they would have missed were developmental.

(2) Does it matter if developmental problems are missed?

Behind this question lie the issues of whether one can effectively, and if so whether one

Table 2 Physical conditions $(n=57)$ for which 54 children required re-examination

\begin{tabular}{ll}
\hline & No of conditions \\
\hline Growth and nutrition (n=27): & 15 \\
Overweight & 1 \\
Underweight & 11 \\
Small stature & 4 \\
Medical ( $=26):$ & 2 \\
Congenital heart disease & 2 \\
Coeliac disease & 5 \\
Asthma & 1 \\
Skin disease & 6 \\
Genitourinary disease & 5 \\
Ear, nose, and throat conditions & 1 \\
Undescended testicle & 2 \\
Debilitation & 1 \\
Orthopaedic (n=4): & 1 \\
Valgus ankle & \\
Deformed finger & Posture
\end{tabular}


should, check the development of children when they start school. As health in children has always to be viewed in a developmental context it is inconceivable to us that there should be any doubt about the need to check development when checking physical state; yet the working party on child health surveillance are curiously ambivalent about this. ${ }^{5}$ They argue that developmental screening tests are scientifically unacceptable as they do not meet the required criteria for such tests (especially as regards sensitivity and specificity); and the same applies to unsolicited developmental examinations as these are screening procedures when offered to all children. They then concede that developmental examination can effectively identify developmental disorder but dismiss its use as unnecessary and/or irrelevant, and finally recommend only that repeated developmental examinations on a routine basis should be discontinued (our italics). More specific objections to developmental examinations are that they are unstandardised, unreliable, and rely on soft neurological signs (for example, clumsiness) for which the range of normality has not yet been clearly defined. ${ }^{25}$

Most of these criticisms stem from the bland but fallacious assumption that any procedure that seeks to identify a disorder (or even a problem, according to the above working party) in a child of which his parents are unaware is a screening procedure and therefore subject to evaluation in terms of the agreed criteria for screening tests ${ }^{89}$-irrespective of the nature or complexity of the procedure and irrespective also of whether or not any such disorder (or problem) meets additional criteria that warrant a screening programme in the first place. This assumption is evident throughout that working party's report but nowhere more blatantly than in their misquote that the working party on school health services also concluded that developmental examination on entry to school was unjustified: what the latter actually recommended was that neurodevelopmental screening should not at present be used routinely. ${ }^{3}$

It is true that some of the tests used in developmental examinations are not as well standardised as others, nor perhaps as reliable, but neither are many of the clinical tests used in standard medical practice. Even in this age of technology clinical medicine remains a very inexact science. It would be plainly ridiculous to require all clinical tests used to elicit abnormal signs to have all the characteristics of screening tests. Ways and means of evaluating developmental examinations are certainly still needed and proving elusive but to discredit them as screening procedures is scientifically dishonest. It is a strange idea, too, that these examinations are said to depend upon soft neurological signs, and one far removed from the neurodevelopmental examination we have described in this journal and that Drillien and Drummond employed. ${ }^{15}$ In these, responses to tests involving sensorimotor skills and speech and language were observed as well as the child's adaptive and social behaviour; such observations, alongside a developmental history and physical, personality, and experiential factors, were then used in arriving at a clinical assessment of the child's developmental status. It calls for a package approach rather than the isolated use of single tests, and herein lies a fundamental difference between screening and examining. The clinician, unlike the screener, does not have to rely upon a single abnormal response to conclude an abnormality is present, nor even possibly present and needing referral. The clinical significance of equivocal responses to individual tests that so nullify their use in screening can usually be gauged in the context of responses to other tests, that is, through the exercise of professional judgment on the part of the examiner.

This was well shown from reliability studies that we carried out. High correlations were achieved between the examiners when all items were included in the assessment, but somewhat lower correlations were found when only abnormal responses were compared. Thus the fingernose test proved to be the one where agreement on abnormal responses only reached about $50 \%$. On the other hand validity studies showed that the test contributed significantly to the child failing the whole battery of tests. Judgments about the finger-nose test are difficult but the test along with others helps to identify the clumsy child. These findings are very similar to those reported in studies of more severely disabled children in the neuropsychiatric studies in childhood ${ }^{16}$; the examiners had disagreed about individual signs but in general reached the same diagnosis.

Developmental examinations of school entrants have also been condemned because they cannot predict which children will eventually require extra help and because the treatment of neurodevelopmental abnormalities that may be found has no impact on associated language or learning difficulties and anyway the minor abnormalities improve spontaneously. ${ }^{25}$ We know opinions differ as to what exactly is the association between neurodevelopmental delay and learning problems but there is convincing evidence that their association is at least statistically very significant. ${ }^{15} 1719$ From our own observations and research findings we have no doubt that the presence of neurodevelopmental delay is a clear indication of the child's vulnerability to adverse experiences and a predisposition to academic and behaviour problems that may persist into teen ages. ${ }^{20} \mathrm{We}$ are also concerned at its relatively high prevalence, $7 \%$. Clinicians may be reassured by the knowledge that statistically it is very likely that the child's neurodevelopmental delay will have been overcome and that not all children at risk do actually experience educational and social failure. These are not, however, sufficient excuses for defeatist and ostrich like clinical practice and they are no consolation for the substantial number of children who do fail.

Of course their difficulties will eventually come to light in school, though on the whole teachers tend to be reluctant to refer any but the most severely handicapped children for investigation until they have been in junior school for a year or two and are obviously failing and they don't know what else to do. But why should a child have to run this gauntlet when his 
difficulties can so often be recognised in embryo' by a doctor at an entrant examination? And what about their secondary effect while the maturity of the child's central nervous system is catching up? Have we already forsaken the preventive tradition of health services in school? Making a diagnosis of neurodevelopmental delay does not mean the child has to be labelled with an untreatable disorder nor that eventually he will need special education. Doctors should always be circumspect in what and how they tell parents and teachers; the use of descriptive terms commonly suffices and can form a basis for symptomatic treatment, a pattern of care so frequently resorted to in the case of physical disease. Thus physiotherapy or pharmacology and remedial teaching may help some children in the short term; guidance and support for parents may help to contain family stress and diminish the scapegoating and rejection of the child that so often stem from ignorance and despair. Maybe teachers are still uncertain of what special educational techniques to employ but they will never discover these if they are never faced with the problem; in the meantime giving them a better understanding of the influences governing a child's performance and behaviour in school may help them to adopt a more appropriate stance toward the child. We are frankly amazed that medical colleagues on the working party on child health surveillance should subscribe to the view that this is an inappropriate ineffective task for doctors because they can only perceive developmental delays and impairments as a form of pathology that requires treatment. ${ }^{5}$ Coupled with the findings from a recent survey of general practitioners interest and training in child health surveillance, ${ }^{21}$ it is a disturbing indication of the prejudice that still exists within conventional medicine against the concept of the integration of preventive and curative care in the child health services.

(3) How much money might be saved by a nurse only health check of entrants?

It is possible to estimate and so compare the costs of joint (doctor and nurse) health checks of all entrants to a typical infant school and of health checks by the nurse alone, by extrapolating from data obtained during our study of health services in Paddington primary schools. ${ }^{12}$ A typical health district of 240000 total population has 100 primary schools within its boundary with 225 pupils per school and an annual intake of 37 children 'rising 5'.

Our joint examination of an entrant takes on average 20 minutes of doctor time and 37 minutes of nurse time. It is seldom feasible for the nurse to test vision (distant, near, and colour, taking five minutes) and hearing (a pure tone audiometric audiometric sweep test taking 10 minutes on average, allowing for a full audiogram on the occasional child who fails the sweep test) when the child and his mother attend a joint examination. In practice it is most convenient for the nurse to do these on a previous day but this does mean that she has also to peruse preschool health records then (taking two minutes). When the parent attends the nurse can then weigh the child, and measure his height and head circumference (taking four minutes), and she has ample time to interview the parent (taking on average eight minutes). As the continuing health care of the child in school will rest principally with the nurse there is much to be said for her being present during the closing stages of the medical examination and discussion with the parent.

Applying (for this theoretical exercise) the current hourly rates of pay, based on the full time midpoint salary scales for school nurse and community medical officer (school doctor) excluding London weighting, the cost of such joint health checks of 37 entrants would be $£ 298 \cdot 81$ (table 3).

If the nurse carried out the health check on her own the nursing time required would be much the same ( 37 minutes) as in a joint check. For in addition to her tasks itemised above (taking 29 minutes) she would need to do a physical inspection (of skin, limbs, and of ears with an auriscope, taking two or three minutes) and she would also need to conclude the check with her own brief discussion with the parent. Even so, this would not mean the authority would save the full cost of the doctor's routine examination of all 37 entrants (that is, $£ 115 \cdot 19$ ) because there would still be some children needing a medical examination solely as a result of the change to a nurse only check. The cost of these examinations would need to be deducted to arrive at a net saving from nurse only checks.

Table 3 Comparative staffing costs for joint doctor and nurse and nurse only health checks of school entrants in a typical health district

(A) For joint health check at each primary school

For joint health check at each primary school
Cost of nurse:

(B) For nurse only health check at each primary school

37 children at 37 minutes per child and $\$ 7.96$ per hour

Cost of doctor: (a) Eight children (with no preschool records) at 20 minutes per child and

(b) 12 children (with possible problems) at 10 minutes per child and

£9.34 per hour

(c) Six children (among those at (b) above) needing neurodevelopmental

(d) 17 children needing check for undescended testicles and/or congenital 
These extra examinations would be: (a) a 20 minute comprehensive examination of children with no preschool health records $(21 \%$ of entrants); (b) an investigation of the children referred by the nurse for a specific reason (32.5\% of entrants); (c) a 12 minute neurodevelopmental assessment of those children referred because they were not speaking clearly in sentences by the age of 3 and/or their behaviour or bedwetting was causing concern to the parents ( $17 \%$ of entrants); and (d) a routine check for undescended testicles and/or congenital heart disease in the remaining $46.5 \%$ of entrants, at the rate of a boy and a girl every five minutes (this check can be done on the children in (a) and (b) above at their special examination).

With regard to the children in (b), this initial investigation of a possible problem would have been incorporated into the 20 minute comprehensive examination of each entrant if there had been joint rather than nurse only health checks. The proportion of such entrants used in our calculations allows for the fact that some have more than one possible problem; costs are apportioned to the number of children examined and not the number of problems. The time required by the doctor to examine each child would depend upon the nature of the suspected problems and how many were present. It would be least for children who fail only their vision test and most for those with a speech and/or language problem and worrying behaviour. We have reckoned it would be 10 minutes per child on average. We know that some districts have arrangements whereby some specialists (for example, speech therapists, ophthalmologists) accept referrals direct from school nurses. We think this is medically unsound and a misuse of specialist resources. It happens most often in the case of children failing their vision tests but this is particularly inappropriate at a time when the criteria for treatment is again being questioned. ${ }^{22}$

The estimated cost of the doctor's time for these examinations is given in table 3, which shows the difference between the overall cost of joint health checks and nurse only checks of entrants is $£ 55$ per school per annum, a sum equivalent to barely two doctor sessions per annum per school. This saving would be appreciably less if, as is quite likely, an assistant school nurse was employed to help with a nurse only check. We have never doubted that nurse only health checks of entrants are cheaper than joint checks but as they are certainly less effective in revealing problems at least in this respect it is not true to say they are more cost effective.

Routine joint examinations of school entrants should be maintained

We believe that as society has decreed that for all its citizens 11 years of schooling be a compulsory experience, in their own right as young dependent citizens each and every child should be entitled to a health check on starting school. We are not alone in regarding this as necessary today as it was 80 years ago. The Court committee, whose philosophy at least is widely accepted, was so strongly of this opinion as to advise that the medical examination of school entrants should again be made mandatory. ${ }^{23}$ An independent, multidisciplinary committee charged with reviewing the child health services 10 years after Court has reaffirmed that every child 'round about the age of 5' should be seen by a doctor ${ }^{24}$; this conclusion has been endorsed by the National Association of Head Teachers. 25

As we understand it, as health is dynamic, such a check does not mean a glance at a past opinion about a child's health scribbled on a preschool health record; as we all know, it is easy to make errors of commission in using ticks or crosses as well as of omission in routine procedures. Nor is it just an inquiry of what his parents may think presently about his health. A proper health check is an on the spot verification by a suitably qualified doctor or nurse acting on behalf of the child, that his physical state is satisfactory and that his functional development and his level of emotional development and social adjustment are appropriate for his age and personal circumstance. If these are so, it should be possible for the child to benefit to the full from enforced education in school; it also becomes possible to plan an individualised programme of subsequent health care in school.

At least half of all school entrants will be found to be physically and developmentally normal. This should be welcomed if one is truly in the business of preventive paediatrics; it is better to be doubly sure than uncertain or ignorant. There are some school doctors unfortunately who are avid for abnormality and regard confirmation of normal health and individual health education with mother and child as a waste of their time. However, most parents do not see it this way, though their views are often overlooked. For instance over $\mathbf{9 9 \%}$ of the Paddington mothers attended their child's entrant examination ${ }^{12}$; and in a national inquiry a few years earlier $93 \%$ of parents interviewed thought medical examinations of schoolchildren were a good idea, a proportion that had not changed over the previous decade. $^{26}$

We do not think a system of selective medical examinations, such as that described by O'Callaghan and Colver, ${ }^{2}$ is a reasonable alternative to routine examinations. It seems to us no more than an attempt to refine the identification of abnormality. It is arbitrary and exclusive rather than selective about whose health should actually be checked. Added to which it relies heavily on the concerns of parents and teachers, and on written records. Adult concern is not a foolproof pointer to childhood disorders; some of these do not necessarily cause concern to either parents or teachers, it depends on how observant they are, their expectation of what is normal, and their threshold of tolerance. Others may cause concern that may not be voiced even when this is invited, as in the case of mothers who are shy, lacking in confidence or inarticulate; but health care should be for all children, not just those whose parents are competent and caring.

As for preschool health records, in our 
Paddington study we found on average just as many problems among children for whom there were records (1.28 per child) as among those without records (1.34 per child). Lucky the child who has no preschool health records: at least he will be seen by a doctor! We are reminded how 'at risk' registers were abandoned because a statistical likelihood of normality proved to be a poor guarantee that this would be found in a particular child whose name was not on the register. As the Warnock committee readily understood of educational difficulties, there is no substitute for informed and systematic observation of all children. ${ }^{27}$

We realise of course that prevalence rates for disorders in school entrants vary widely, not only from health district to health district but from school to school (in our experience from 73 to $26 \%$ ). Nevertheless, we do wonder how much of the striking differences between the rates in Paddington and in Cramlington, respectively 41 and $1.4 \%$, with only one problem occurring in 73 of the latter children with no preschool records, may be accounted for by the different ways in which health checks were carried out, particularly the omission of neurodevelopmental assessment of entrants in Cramlington. We deplore the current reductionist policy in service provision: if in doubt just cut it out. No prior study is mentioned by O'Callaghan and Colver of what might be missed by eliminating the medical role in routine health checks.

Another obvious reason might be the fact that a doctor had already examined many of the Cramlington entrants at the age of 4 to 4.5 years. We cannot see the need for such an examination unless it is clearly related to imminent admission to infant school. Under these circumstances it would be logical for the doctor to examine after entry only those children who were not known to have been examined during the previous 12 months. If one wants to describe this as selective examination we would not argue the point. As a matter of interest it was the neighbouring city of Newcastle upon Tyne that pioneered the use of routine medical examinations of children just before their entry to school. ${ }^{28}$ We know of another 10 local education authorities that followed suit, ${ }^{29}$ and the Court committee was readily convinced of their value both as a preventive child health care procedure and in establishing an integrated child health service involving general practitioners as general practitioners paediatricians in education medicine. As year after year slips by of disintegrated services this has become a pipe dream and interest in purposeful pre-entry school medical examinations has waned. They have usually been carried out in health service clinics, which have far better facilities for the examinations and save nurses' time while allowing them more scope,${ }^{30}$ but they have one serious disadvantage. The removal of the examinations from school premises reduces the medical presence in the school and makes mutual understanding, respect, and communication, and therefore cooperation between teachers and the school doctor and nurse much more difficult to achieve and maintain.
At least one can be sure that every child would be seen when nurse only checks are used but in discovering problems the nurse cannot go it alone. One in five of physical disorders might be missed and half of those associated with development. No service should be content to operate at a $73 \%$ effective level when it could knowingly do better, particularly if this also means greater customer convenience. One of the disadvantages of nurse only health checks is that the parents have to attend twice-unless (heaven forbid) the doctor has an annual 'balls and murmur' session without the parents being present-a very questionable practice. Even then one out of three of the parents would have to return for the doctor to sort out children with problems suspected by the nurse, a task normally carried out within the 20 minutes allotted on average to a routine medical examination.

The simple truth is that if only so much as a check of testes and heart has to be done and by the doctor-and no one has yet dared to suggest otherwise-the nurse only check becomes a joint check. The only question then is: which is the best way for doctor and nurse to share in the task of checking health? We would not want to be too dogmatic in answering this. Generally speaking, as the doctors have to do some of the physical examination it is sensible that they do it all; and they need to do the developmental testing, though as we have suggested some of this can be shared with the nurse. The nurses have traditionally taken measurements and tested vision and hearing and they do it very well. However, arrangements between doctor and nurse do have to be flexible. What suits one pair in one school may not be satisfactory in another school, nor suit another pair. Similarly, when they know their schools and catchment areas, and have learned that they can rely upon the information on preschool records, they should use their own discretion as to how comprehensive an examination they give a child to be satisfied about his health. This applies particularly to developmental assessment. The frequency with which individual children need to be seen again, and by whom, is always a matter of clinical opinion. This is universally understood and accepted in the case of children who have problems; to do otherwise would be to challenge the principle of clinical autonomy. Yet this is exactly what is done in the case of children who do not yet have problems! It is not the function of health authorities, nor of their more senior doctors and nurses, to lay down programmes of health checks indiscriminately for all children in all schools, and the division of labour between doctors and nurses. This is the responsibility of the doctor and nurse allocated to each school, and it is the only way in which properly individualised health care in school can be organised. It has also to be remembered that school doctors and nurses have a responsibility for the school as a community and not just for individual children.

1 Board of Education. Circular 576. London: HMSO, 1907. 2 O'Callaghan EM, Colver AF. Selective medical examination on starting school. Arch Dis Child 1987;62:1041-3.

3 British Paediatric Association. The school health services. London: British Paediatric Association, 1987. 
4 Hall DMB. The child with a handicap. Oxford: Blackwell Scientific Publications, 1984.

5 Hall DMB, ed. Health for all children. Oxford: Oxford Medical Publications, 1989.

6 Fawcett-Henesy A. Health services in school: what do school nurses want? London: Report of the Seventy Third Annual nurses want? London: Report of the Seventy Third Annual Welfare, 1984

7 Health Visitors' Association. Health visiting and school nursing reviewed. London: Health Visitors Association, 1987.

8 Wilson JMG, Jungner G. Principles and practice of screening for disease. Geneva: World Health (WHO Public Health Papers No 34 .

9 Cochrane AL, Holland WW. Validation of screening procedures. BrMed Bull 1971;27:3-8.

10 Whitmore K, Bax M. Annotation: screening or examining? Dev Med Child Neurol 1988;30:673-6.

11 De Angelis C, Berman B, Oda D, Meeker R. Comparative values of school physical examinations and mass screening tests. F Pediatr 1983;102:477-81.

$12 \mathrm{Bax} M$, Whitmore $\mathrm{K}$. The health service needs of children in primary school. London: Kensington, Chelsea and Westminster Area Health Authority, 1981.

13 Whitmore $\mathrm{K}$, Bax $M$. The school entry medical examination. Arch Dis Child 1986;61:807-17.

14 Chinn S, Morris RW. Standards of weight-to-height for English children aged 5-10 years. Ann Hum Biol 1980;7: E57-71.

15 Drillien C, Drummond M. Developmental screening and the child with special needs. Clinics in Developmental Medicine child with special needs. Clinics in Developmental Medicine No 86. London: Spastics Internatio

16 Rutter M, Tizard J, Whitmore K. Education, health and behaviour. London: Longman, 1981.

$17 \mathrm{Bax} M$, Whitmore $K$. The medical examination of children on entry into school: the results and use of neurodevelopmental assessment. Dev Med Child Neurol 1987;29:40-55.

18 Haddlers-Algra M. Correlates of brain dysfunction in children. follow-up study. Groningen: Drukkerij van Denderen BV, 1987.

19 Gillberg IC Children with minor neurodevelopmental disorders, III: neurological and neurodevelopmental problems at age 10. Dev Med Child Neurol 1985;27:3-16.

20 Gillberg IC Gillberg C. Children with preschool minor neurodevelopmental disorders IV: behaviour and school neurodevelopmental disorders IV: behaviour and school 3-13.

21 Marsh GN, Russell D, Russell IT. Is paediatrics safe in eneral practitioners' hands? A study in the north of England. F $R$ Coll Gen Pract 1989;39:138-41.

22 Stewart-Brown S. Visual defects in school children: screening policy and educational implications. In: MacFarlane A, ed. Progress in child health. London: Churchill Livingstone, 1987;14-137.

23 Committee on Child Health Services. Fit for the future. Vol 1 London: HMSO, 1976. (Cmnd 6684.) (Court report.)

24 National Children's Bureau. Child health 10 years after the Court report. Report of the policy and practice review group. London: National Children's Bureau, 1987.

25 National Association of Head Teachers. The NAHT view on the future requirements for school health service provision. School health services. London: British Paediatric Association, 1987.

26 Lucas S. Some aspects of child health care: contacts between children, general practitioners and school doctors. Community Med 1980;2:200-18.

27 Warnock report. Special educational needs-report of the committee of enquiry into the education of handicapped children and young people. London: HMSO, 1978. (Cmnd children

28 Mellor MR, Jones JT, Pearson RCM. Preliminary survey of pre-school medical examinations at five years of age. Medical Officer 1964, 20 November.

29 McGregor A, Atkins CM. Pre-entry school medical inspection. Medical Officer, 1969, 27 June.

30 Slack P. School nursing. London: Ballière Tindall, 1978. 